\title{
Evaluation of the early outcomes of partial urogenital sinus mobilization in females with congenital adrenal hyperplasia
}

\author{
Ahmed Oshiba ${ }^{1,2^{*}}$, Khaled Ashour ${ }^{1}$, Ahmed Khairi', Sameh Shehata ${ }^{1}$, Shaymaa ElSayed ${ }^{3}$ and Essam Elhalaby ${ }^{4}$
}

\begin{abstract}
Background: Congenital adrenal hyperplasia (CAH) is the most common cause of ambiguous genitalia with an incidence of 1 in 15,000 live births. Surgical reconstruction for girls with CAH and urogenital sinus (UGS) is a great challenge to create normal appearing and functional external genitalia. The purpose of this study is to evaluate the early outcomes of using partial urogenital sinus mobilization in feminizing genitoplasty in females with congenital adrenal hyperplasia regarding vaginal caliber, urinary continence, and genital appearance.

Results: Patient age at surgery ranged from 4 to 96 months (mean 19.4 months), with a mean follow-up of 15 months. Degree of virilization was Prader type III in 2 children (8\%), type IV in 18 (72\%), and type V in 5 (20\%). Urogenital sinus length was $2.5 \mathrm{~cm}$ or less in 18 children. Cosmetic results were good in 19 patients (76\%) and satisfactory in 6 (24\%). Adequate caliber of the mobilized vagina was achieved in 24 patients (96\%). Seven toilet trained children were assessed for bladder function. Only 1 patient was daytime incontinent and improved after few months with regular voiding. Urodynamics was done in toilet trained children and showed normal results.

Conclusions: The surgical procedure in general is consisting of clitoroplasty, labioplasty, urethroplasty, and vaginoplasty. Separation of the vagina from the urethra is a highly challenging surgical step and need good experience to perform. Partial urogenital sinus mobilization (PUM) has good results regarding the urinary continence, vaginal diameter, and cosmetic results in CAH patients.
\end{abstract}

Keywords: Urogenital sinus mobilization, Congenital adrenal hyperplasia, Clitoroplasty, Vaginoplasty

\section{Background}

Congenital adrenal hyperplasia $(\mathrm{CAH})$ is the most common cause of ambiguous genitalia with an incidence of 1 in 15,000 live births [1]. Surgical reconstruction for girls with CAH and urogenital sinus (UGS) is a great challenge to create normal appearing and functional external genitalia, preserving bladder function, and normal sexual and reproductive adult life [2]. The level of vaginal insertion and the degree of virilization are the main determinant factors in the reconstruction.

\footnotetext{
*Correspondence: ahmed_eshiba2012@yahoo.com

'Department of Pediatric Surgery, Faculty of Medicine, Alexandria University Hospitals, Alexandria, Egypt

${ }^{2}$ El Shatbi University Hospital, Shatbi, Alexandria, Egypt

Full list of author information is available at the end of the article
}

Nowadays, we are in the era of one stage reconstruction [2-4]. Rink et al. [5] started to apply Pena concept regarding total urogenital sinus mobilization (TUM) in patients with CAH. By doing this, they achieved good cosmetic results with fewer complications. Despite good cosmetic results were achieved, the risk of urinary incontinence was high due to aggressive dissection of the bladder neck. For this reason, Rink et al. eventually developed the concept of partial urogenital sinus mobilization (PUM) [6]. This modification mainly consists of sparing the pubourethral ligaments (PULs), avoiding aggressive mobilization of the urogenital sinus (UGS) at the inferior border of the symphysis pubis. We present a prospective study followed these children who treated with PUM.

\section{Springer Open}

(๑) The Author(s). 2020 Open Access This article is licensed under a Creative Commons Attribution 4.0 International License, which permits use, sharing, adaptation, distribution and reproduction in any medium or format, as long as you give appropriate credit to the original author(s) and the source, provide a link to the Creative Commons licence, and indicate if changes were made. The images or other third party material in this article are included in the article's Creative Commons licence, unless indicated otherwise in a credit line to the material. If material is not included in the article's Creative Commons licence and your intended use is not permitted by statutory regulation or exceeds the permitted use, you will need to obtain permission directly from the copyright holder. To view a copy of this licence, visit http://creativecommons.org/licenses/by/4.0/. 


\section{Methods}

After obtaining parental consent, we prospectively followed 25 girls with $\mathrm{CAH}$ who underwent PUM during a 2-year period. Twenty-three cases were salt losers while 2 cases were simple virilizing. Degree of virilization is reported based on the Prader scale.

Medical management was performed under the guidance of a pediatric endocrinologist. All children with $\mathrm{CAH}$ received "stress dose" steroid replacement at the time of surgery according to the endocrinologist/ anesthetist protocol for $\mathrm{CAH}$ patients.

\section{Surgical procedure}

Before surgical reconstruction, cystoscopy was performed to determine the length of the common channel and the level of the urethrovaginal confluence. A Foley catheter was placed in the vagina. The child was set in a supine position with both legs hold to an inverted Ushaped bar fixed at the end of the operating table.

Briefly, after making a circumferential incision around the UGS, a .5-1 cm mucosal strip was demarcated and preserved below the clitoris. The incision was then extended toward the anus up to the apex of an inverted perineal " $U$ " incision. The perineal flap (Fortunoff flap) was demarcated anteriorly to the anus reaching to the expected site for vaginal introitus. It is usually a broadbased flap. Circumferential dissection was then started at the posterior aspect of the UGS, in front of the rectum. Anteriorly, the dissection extended to the inferior border of the symphysis pubis, keeping the PULs and minimizing the degree of lateral dissection above the levator ani muscles.

We continued the dissection until the Foley catheter was palpated posteriorly. At that point, an incision was made at the posterior wall of the vagina till appearing of a normal vaginal mucosa. Eventually, the vagina was dismembered from the rectum, permitting the vaginal introitus to reach the perineum without tension. Finally, a wide vaginal opening was fashioned by suturing it to a Fortunoff flap in (24 cases) [7].

In cases of low UGS (less than $2.5 \mathrm{~cm}$ ), the common channel was dissected and pulled till the urethrovaginal confluence extended to the perineum, and its distal part was ventrally incised, allowing us to create a mucosal lined vestibule (7 patients).

In cases of high UGS (greater than $2.5 \mathrm{~cm}$ ), the vagina was disconnected at the junction with the urethra, with limited dissection in its distal portion to allow closure of the UGS (which later becomes part of the urethra). This technique also provides the distal part of the UGS to be part of the anterior wall of the vagina.

This flap is built by opening the UGS at 12 o'clock, this mucosa is inverted posteriorly to construct the distal anterior wall of the vagina (Passerini flap) in 18 cases.
An incision was made in the midline of the posterior wall of the vagina to avoid vaginal stenosis.

Sub-tunical clitoroplasty was the preferred technique in this study. Resection of erectile tissues was carried out in all cases according to the repair described by Kogan et al. [8] with preservation of the neurovascular bundle. We performed glans reduction in 18 patients by removing a lateral wedge ventrally from it. The dorsal phallic skin was used to reconstruct the labia minora. Labia majora flaps were built from V-Y incisions following the scrotal folds to reconstruct a normal vestibule. Operative steps in Prader IV and V patients are declared in Figs. 1 and 2.

\section{Follow-up}

All children were followed at a mean follow up of 15 months. Cosmetic results were decided according to genital symmetry, clitoral size, vaginal position, and genital skin quality (following modified criteria of Creighton et al.) [9]. Based on these parameters, genital appearance was considered good if all criteria were accomplished, satisfactory if up to 2 anomalies were obtained.

Vaginal diameter was determined by gentle calibration with the largest suitable Hegar dilators after performing perineal inspection.

Urinary continence was determined by voiding diary and ultrasound measurement of post-void residual in toilet trained patients. Also, voiding cystourethrogram (VCUG) was done after 3 months to assess the urethral caliber, length, and bladder configuration. Urodynamics also was asked in toilet trained children after 3 months to assess the bladder capacity and the urethral function in these patients.

After completion of data collection, data was revised, coded, and fed to the computer and analyzed using the SPSS software package version 23. Quantitative data was described using the mean and the standard deviation. Qualitative data were described using number and percent.

\section{Results}

Two cases of CAH (8\%) were classified as Prader type III, $18(72 \%)$ as type IV, and $5(20 \%)$ as type V. Of 25 children evaluated by cystoscopy, the urethrovaginal confluence from the perineal skin surface was determined to be less than $2.0 \mathrm{~cm}$ in $3(12 \%), 2.0 \mathrm{~cm}$ in 6 (24\%), $2.5 \mathrm{~cm}$ in $9(36 \%)$, and $3.0 \mathrm{~cm}$ or greater in 7 (28\%).

Patient age at surgery ranged from 4 to 96 months (mean 19.4 months, median 10.0 months). Table 1 shows patient characteristics, length of UGS, and follow-up of each child. At a mean follow-up of 15.44 months, genital appearance was considered good in 19 children (76\%) and satisfactory in 6 (24\%).

In 21 of the patients (84\%), clitoral head size was accepted and hidden in the vestibule; in 2 cases $(8 \%)$, it 


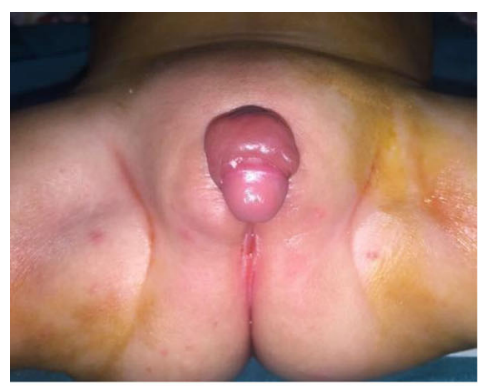

a. Prader IV patient 2 years old child.

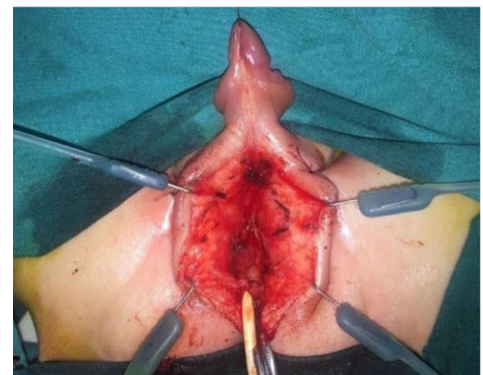

c. UGS mobilization and circumferential d. S dissection.



e. Starting the dissection of the prepuce and glanular reduction.

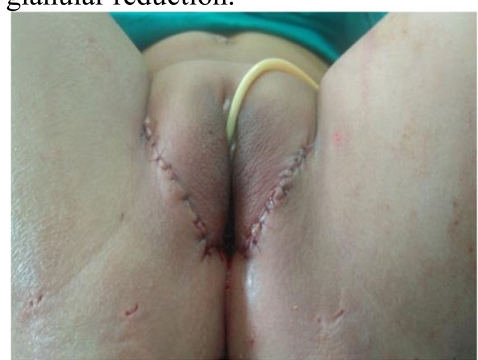

g. Final shape by the end of the procedure.

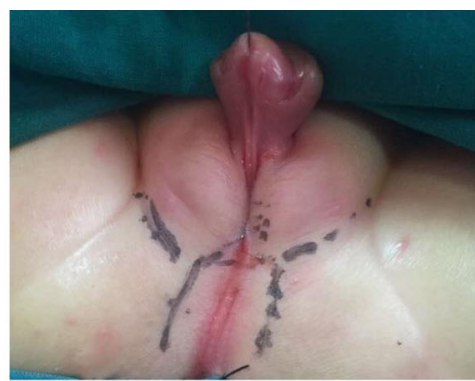

b. Marking showing the limit of posterior perineal flap.



hegar dilator in the vagina.



f. Labioplasty.



h. 2 months later postoperative.

Fig. 1 a Prader IV patient 2 years old child. b Marking showing the limit of posterior perineal flap. c UGS mobilization and circumferential dissection. $\mathbf{d}$ Separation of the vagina from the urethra with hegar dilator in the vagina. e Starting the dissection of the prepuce and glanular reduction. $\mathbf{f}$ Labioplasty. $\mathbf{g}$ Final shape by the end of the procedure. $\mathbf{h} 2$ months later postoperative

was large in the follow-up period ( 1 of them was badly controlled by the corticosteroid and needed to upgrade the dose), and in 2 patients (8\%) it was small and atrophic one.

Twenty-two of the patients (88\%) showed vaginal orifice at the surface of the perineum while 3 of them (12\%) were deeply seated in the vestibule. All of them were examined under general anesthesia to calibrate the vagina and urethra after mean follow-up of 6 months. Only 1 case was stenosed during vaginal examination and planned for regular dilatation under sedation.

A total of 7 patients (28\%) were toilet trained and evaluated for urinary continence. Six of those toilet trained children were fully continent day and night. Only 1 of them complained of daytime incontinence and relieved after few months of follow-up. 




a. Preoperative prader V in 5 months old baby.

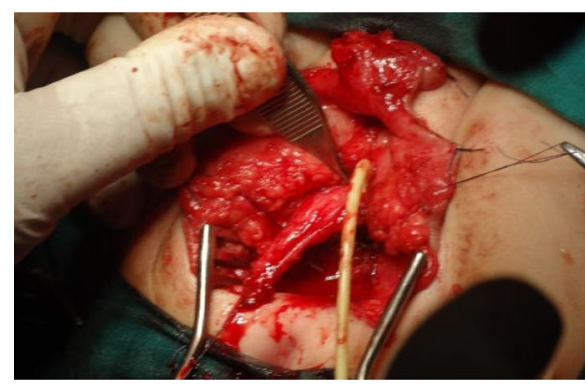

c. UGS dissection

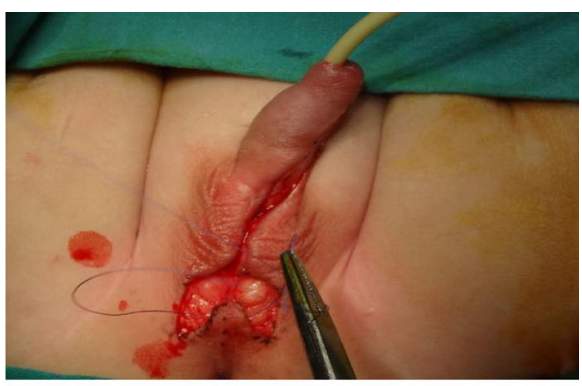

b. Dissection of the perineal flap.

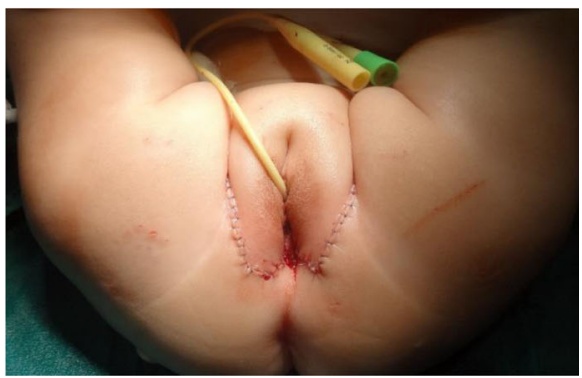

d. Final result by the end of the procedure.

Fig. 2 a Preoperative Prader $V$ in 5 months old baby. b Dissection of the perineal flap. c UGS dissection. $\mathbf{d}$ Final result by the end of the procedure

Urodynamics study was done to those who are toilet trained after 3 months, and it showed completely normal study. A total of 25 patients performed VCUG after 3 months to evaluate the urethral length and the bladder capacity. All of them showed normal study with good urethral length and normal bladder configuration as shown in Fig. 3.

\section{Discussion}

Congenital adrenal hyperplasia $(\mathrm{CAH})$ is the commonest cause of ambiguous genitalia in females [1]. The surgical procedure in general is consisting of clitoroplasty, labioplasty, urethroplasty, and vaginoplasty [10]. Separation of the vagina from the urethra is a highly challenging surgical step and need good experience to perform [3, 11, 12].

Urinary incontinence, vaginal or urethral stenosis, and recurrent urethrovaginal fistula are the most popular postoperative problems. To facilitate reconstruction and decrease the risk of complications, TUM was initially described to repair cloacas [4]. Rink et al. [5] started to use the technique of TUM in patients with CAH. This repair is permitting easy mobilization of the urethrovaginal confluence, with repositioning of the urethral and vaginal orifices in a separate orthotopic location.

Although the risk of injury of the urinary sphincters is decreased, damaging of the PULs during total mobilization has raised attention regarding postoperative urinary incontinence. Long-term follow-up is mandatory to be able to judge the full continence. For example, Kryger and Gonzalez reported preserved urinary continence in 9 children with CAH after TUM [13]. Also, Palmer [14] reported in his study about urinary incontinence comparing PUM and TUM in UGS and cloacal anomalies that there is no difference regarding the urinary continence.

If surgical results are not compromised, we prefer to spare the PULs, since we agree with the findings of Farkas et al. [3] and Passerini [15] that it is easy to preserve the sphincteric mechanism during the dissection. In our series, the urethrovaginal confluence was taken down to the perineum in all children using PUM and a perineal inverted $U$ flap if needed. In 18 patients, the urethra had to be separated from the vagina, closing the urethrovaginal fistula and a Passerini flap [15] used to create the anterior vaginal wall. This approach made it easier to preserve the PULs without disrupting the sphincteric mechanisms.

In our series, PUM was performed together with clitoroplasty, with keeping the neurovascular bundle intact and labial reconstruction. Clitoroplasty was done following the procedure of Kogan et al. [8] glanular wedge reduction in 18 patients to increase the chances for normal sensation and function during sexual arousal. We believe that careful nerve sparing clitoroplasty is preferable to a resection approach in girls with a large clitoris [16-18]. The long-term follow-up is mandatory to judge the sexual satisfaction to those who grow up with large clitoris. 
Table 1 Patients' characteristics and operative procedures

\begin{tabular}{|c|c|c|c|c|c|}
\hline No. & Age (months) & Prader classification & UGS length $(\mathrm{cm})$ & Vaginoplasty & Follow-up (months) \\
\hline 1 & 7 & IV & 2.5 & $\mathrm{PUM}+\mathrm{P}+\mathrm{F}$ & 24 \\
\hline 2 & 12 & IV & 2.5 & $\mathrm{PUM}+\mathrm{P}+\mathrm{F}$ & 24 \\
\hline 3 & 96 & V & 3.5 & $\mathrm{PUM}+\mathrm{P}+\mathrm{F}$ & 22 \\
\hline 4 & 27 & IV & 2.5 & $\mathrm{PUM}+\mathrm{P}+\mathrm{F}$ & 22 \\
\hline 5 & 24 & IV & 2.5 & $\mathrm{PUM}+\mathrm{P}+\mathrm{F}$ & 22 \\
\hline 6 & 7 & III & 2 & $\mathrm{PUM}+\mathrm{F}+\mathrm{MV}$ & 19 \\
\hline 7 & 5 & IV & 2.5 & $\mathrm{PUM}+\mathrm{P}+\mathrm{F}$ & 19 \\
\hline 8 & 5 & III & 2 & $\mathrm{PUM}+\mathrm{F}+\mathrm{MV}$ & 17 \\
\hline 9 & 48 & IV & 1 & $\mathrm{PUM}+\mathrm{F}+\mathrm{MV}$ & 17 \\
\hline 10 & 5 & IV & 2 & $\mathrm{PUM}+\mathrm{F}+\mathrm{MV}$ & 17 \\
\hline 11 & 5 & V & 3.5 & $\mathrm{PUM}+\mathrm{P}+\mathrm{F}$ & 16 \\
\hline 12 & 12 & IV & 1.5 & $\mathrm{PUM}+\mathrm{F}+\mathrm{MV}$ & 16 \\
\hline 13 & 7 & IV & 3 & $\mathrm{PUM}+\mathrm{P}+\mathrm{F}$ & 16 \\
\hline 14 & 5 & V & 3 & $\mathrm{PUM}+\mathrm{P}+\mathrm{F}$ & 16 \\
\hline 15 & 10 & IV & 2 & $\mathrm{PUM}+\mathrm{P}+\mathrm{F}$ & 13 \\
\hline 16 & 48 & IV & 2.5 & $\mathrm{PUM}+\mathrm{P}+\mathrm{F}$ & 11 \\
\hline 17 & 60 & IV & 3 & $\mathrm{PUM}+\mathrm{P}+\mathrm{F}$ & 11 \\
\hline 18 & 18 & V & 2.5 & $\mathrm{PUM}+\mathrm{P}+\mathrm{F}$ & 11 \\
\hline 19 & 12 & IV & 2 & $\mathrm{PUM}+\mathrm{F}+\mathrm{MV}$ & 8 \\
\hline 20 & 32 & IV & 3 & $\mathrm{PUM}+\mathrm{P}+\mathrm{F}$ & 8 \\
\hline 21 & 4 & IV & 2.5 & $\mathrm{PUM}+\mathrm{P}+\mathrm{F}$ & 13 \\
\hline 22 & 5 & IV & 2 & $\mathrm{PUM}+\mathrm{P}+\mathrm{F}$ & 13 \\
\hline 23 & 9 & V & 3.5 & $\mathrm{PUM}+\mathrm{P}+\mathrm{F}$ & 7 \\
\hline 24 & 14 & IV & 2.5 & $\mathrm{PUM}+\mathrm{P}+\mathrm{F}$ & 10 \\
\hline 25 & 8 & IV & 1.5 & $\mathrm{PUM}+\mathrm{F}+\mathrm{MV}$ & 14 \\
\hline
\end{tabular}

One of the strengths of our series is the fact that all children performed vaginal calibration under sedation after 6 months of follow-up; there was no significant vaginal stenosis except in 1 child. Braga et.al [18]. reported in his study with PUM in 24 CAH patients that vaginal stenosis occurred in only 1 case and needed for revision.

In our series, deep vaginal opening occurred early in 3 cases because the posterior wall of the vagina was not fully separated and incised. From this observation, we have learned that the first few centimeters of the vagina can be fibrotic and narrow, and if not opened widely and sutured to a skin flap at the vestibule will result in a deeply seated and narrow vaginal opening.

If the urethrovaginal confluence is more than $2 \mathrm{~cm}$ away from the perineum, some authors have decided delaying vaginoplasty till puberty, as the effect of high
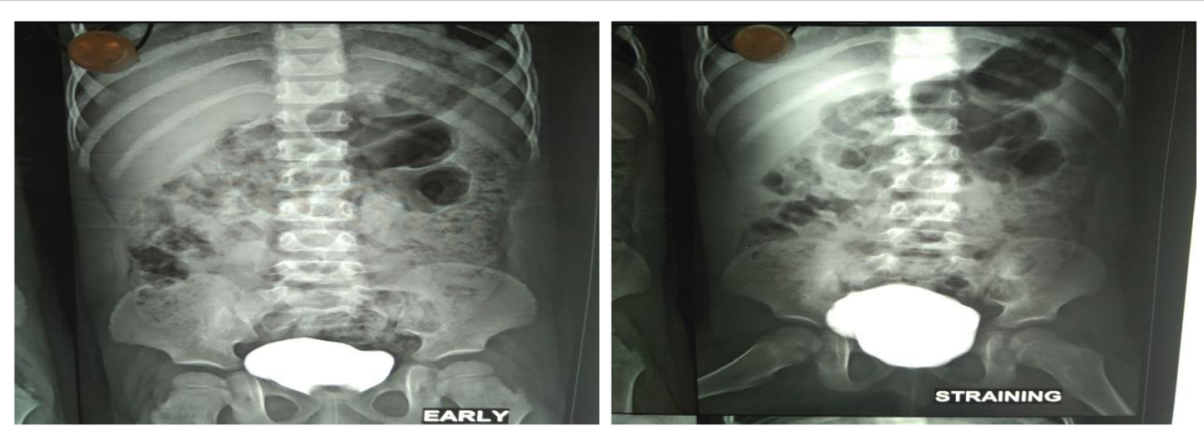

Fig. 3 VCUG in 9 years patient showing normal bladder configuration during early and voiding phases 
hormone at puberty will seriously decrease the incidence of vaginal stenosis $[16,17]$. One disadvantage of this approach is that a staged repair with clitoroplasty at infancy followed by later vaginoplasty after puberty would limit the technical options, as the preputial skin would have been reconstructed before. Also, it is so difficult to use the remnants of the UGS for vaginal reconstruction $[12,18,19]$.

Even if vaginal stenosis occurred after a 1-stage repair, it is technically easier to revise this short stenosis after puberty than doing the whole pull-through vaginoplasty at that time $[18,20]$. Only in cases where the vagina is severely hypoplastic and likely to require replacement with nonvaginal tissue do we believe it is wise to delay vaginoplasty until post pubertal age. It has been found that atretic vagina may become large enough in response to pubertal hormones and physiological menstruation, seriously to decrease the use of nonvaginal tissue [21].

In our study, the youngest child was 4 months old at surgery, and the operation was easily performed, with excellent exposure. Based on our results in 12 patients undergoing surgery before age of 1 year, we encourage early clitoroplasty and vaginoplasty in all, but the extremely rare example in which the vagina is high and atretic. Early repair gives us the advantage of easier exposure and dissection due to changes in genitalia under the effect of high levels of maternal hormones; also, it appears to permit for increased mobility of the structures and availability of tissues for the upcoming reconstruction [18, 22, 23].

Deciding when and in which patients to perform feminizing genitoplasty has always been difficult. Recent articles have increased our awareness of the potential long-term results of early feminizing genitoplasty by giving away occasional gender dysphoria as well as poor cosmetic results in women who were operated in infancy $[17,18]$.

Based on these results, some authors advise delaying surgical treatment until the age at which the patient manifests interest in having the genitalia repaired. Delaying repair in DSD patients may have bad effect as described by Clayton et al. [1]. Our main target in early gender assignment is to reduce parental anxiety and allow children to grow with better self-esteem and more secure with their femininity $[1,18]$. Recent studies showed that most of those females with $\mathrm{CAH}$ preferred to decide early repair during infancy [24].

In our study, 7 toilet trained patients were evaluated by urodynamics to study the bladder function, detrusor overactivity, and if any urethral abnormalities [18]. None of them showed any abnormalities in the urodynamics even the patient who was complaining of daytime incontinence and improved few months later. Zaccara et al. [25] in his study comparing $\mathrm{CAH}$ and cloaca regarding the bladder function showed also no abnormalities in the urodynamics in the group of $\mathrm{CAH}$.
In our study, VCUG was performed in all of our patients giving us good picture about the bladder configuration, urethral length, and ureteral abnormalities. No bladder abnormalities, urethral strictures, or ureteral anomalies were documented in our study.

Number of the cases and the limited time for followup were our main limitations. So our plan is to continue the follow-up for those cases and give long-term results.

\section{Conclusions}

Feminizing genitoplasty using PUM by perineal approach is an appropriate option for females with $\mathrm{CAH}$ and ambiguous genitalia. Good cosmetic appearance with adequate vaginal introitus as well as urinary continence can be achieved in the majority of patients.

\section{Abbreviations}

$\mathrm{CAH}$ : Congenital adrenal hyperplasia; F: Fortunoff; MV: Mucosal lined vestibule; P: Passerini-Glazel; PUL: Pubourethral ligament; PUM: Partial urogenital sinus mobilization; TUM: Total urogenital sinus mobilization; UGS: Urogenital sinus; DSD: Disorders of sexual differentiation

\section{Acknowledgements}

Not applicable.

\section{Authors' contributions}

All authors have read and approved the manuscript.

- Study conception and design: AK.

- Data acquisition: $\mathrm{AO}$ and $\mathrm{EH}$.

- Analysis and data interpretation: KA.

- Drafting of the manuscript: SE.

- Critical revision: SS.

- Submit this form with the manuscript: AO.

\section{Funding}

No funding resources.

\section{Availability of data and materials}

The datasets used and/or analyzed during the current study are available from the corresponding author on reasonable request

Ethics approval and consent to participate

Not applicable

\section{Consent for publication}

Not applicable

\section{Competing interests}

No competing of interest

\section{Author details}

'Department of Pediatric Surgery, Faculty of Medicine, Alexandria University Hospitals, Alexandria, Egypt. ${ }^{2}$ El Shatbi University Hospital, Shatbi, Alexandria, Egypt. ${ }^{3}$ Department of Pediatric Endocrinology, Faculty of Medicine, Alexandria University Hospitals, Alexandria, Egypt. ${ }^{4}$ Department of Pediatric Surgery, Faculty of Medicine, Tanta University Hospitals, Tanta, Egypt.

Received: 21 January 2020 Accepted: 8 April 2020

Published online: 06 May 2020

\section{References}

1. Group JLECW. Consensus statement on 21-hydroxylase deficiency from the Lawson Wilkins pediatric Endocrine Society and the European Society for Paediatric Endocrinology. J Clin Endocrinol Metabol. 2002;87(9):4048-53.

2. Donahoe PK, Gustafson ML. Early one-stage surgical reconstruction of the extremely high vagina in patients with congenital adrenal hyperplasia. J Pediatr Surg. 1994;29(2):352-8. 
3. Farkas A, Chertin B, Hadas-Halpren I. 1-Stage feminizing genitoplasty: 8 years of experience with 49 cases. J Urol. 2001;165(6 Part 2):2341-2346.

4. Peña A. Total urogenital mobilization - an easier way to repair cloacas. Journal of pediatric surgery. 1997;32(2):263-8.

5. Rink R, Pope J, Kropp B, Smith E, Keating M, Adams M. Reconstruction of the high urogenital sinus: early perineal prone approach without division of the rectum. J Urol. 1997;158(3):1293-7.

6. Rink R, Metcalfe P, Cain M, Kaefer M, Casale A, Meldrum K, editors. Partial urogenital mobilization: the advantages without the risks. annual meeting of European Society for Pediatric Urology and American Academy of Pediatrics, Uppsala, Sweden; 2005.

7. Fortunoff S, Lattimer J, Edson M. Vaginoplasty technique for female pseudohermaphrodites. Surg Gynecol Obstetrics. 1964;118:545-8.

8. Kogan SJ, Smey P, Levitt SB. Subtunical total reduction clitoroplasty: a safe modification of existing techniques. J Urol. 1983:130(4):746-8.

9. Creighton SM, Minto CL, Steele SJ. Objective cosmetic and anatomical outcomes at adolescence of feminising surgery for ambiguous genitalia done in childhood. The Lancet. 2001;358(9276):124-5.

10. Leslie JA, Cain MP, Rink RC. Feminizing genital reconstruction in congenital adrenal hyperplasia. Indian J Urol. 2009;25(1):17.

11. Hamza AF, Soliman HA, Hay SAA, Kabesh AA, Elbehery MM. Total urogenital sinus mobilization in the repair of cloacal anomalies and congenital adrenal hyperplasia. J Pediatr Surg. 2001;36(11):1656-8.

12. Jenak R, Ludwikowski B, Gonzalez R. Total urogenital sinus mobilization: a modified perineal approach for feminizing genitoplasty and urogenital sinus repair. J Urol. 2001:165(6 Part 2):2347-9.

13. Kryger JV, GONZálEZ R. Urinary continence is well preserved after total urogenital mobilization. J Urol. 2004;172(6 Part 1):2384-6.

14. Palmer BW, Trojan B, Griffin K, Reiner W, Wisniewski A, Frimberger D, et al. Total and partial urogenital mobilization: focus on urinary continence. The Journal of urology. 2012;187(4):1422-6.

15. Passerini-Glazel G. A new 1-stage procedure for clitorovaginoplasty in severely masculinized female pseudohermaprodites. J Urol. 1989;142(2):565-8.

16. Minto CL, Liao L-M, Woodhouse CR, Ransley PG, Creighton SM. The effect of clitoral surgery on sexual outcome in individuals who have intersex conditions with ambiguous genitalia: a cross-sectional study. The Lancet. 2003:361(9365):1252-7.

17. Creighton SM. Long-term outcome of feminization surgery: the London experience. BJU Int. 2004:93:44-6.

18. Braga LH, Lorenzo AJ, Tatsuo ES, Silva IN, Salle JLP. Prospective evaluation of feminizing genitoplasty using partial urogenital sinus mobilization for congenital adrenal hyperplasia. J Urol. 2006;176(5):2199-204.

19. Gonzalez R, Fernandes ET. Single-stage feminization genitoplasty. The Journal of urology. 1990;143(4):776-8

20. Krege S, Walz K, Hauffa B, Körner I, Rübben H. Long-term follow-up of female patients with congenital adrenal hyperplasia from 21-hydroxylase deficiency, with special emphasis on the results of vaginoplasty. BJU Int. 2000:86(3):253-8.

21. Hendren WH, Donahoe PK. Correction of congenital abnormalities of the vagina and perineum. J Pediatr Surg. 1980;15(6):751-63.

22. de Jong TP, Boemers TM. Neonatal management of female intersex by clitorovaginoplasty. J Urol. 1995;154(2):830-2.

23. Elhalaby EA. One-stage feminizing genitoplasty in patients with congenital adrenal hyperplasia. Ann Pediatr Surg. 2006;2(2):88-98.

24. Wisniewski AB, Migeon CJ, Malouf MA, Gearhart JP. Psychosexual outcome in women affected by congenital adrenal hyperplasia due to 21 -hydroxylase deficiency. J Urol. 2004;171(6):2497-501.

25. Camanni D, Zaccara A, Capitanucci ML, Mosiello G, lacobelli BD, De Gennaro M. Bladder after total urogenital mobilization for congenital adrenal hyperplasia and cloaca_does it behave the same? J Urol. 2009;182(4S): 1892-7.

\section{Publisher's Note}

Springer Nature remains neutral with regard to jurisdictional claims in published maps and institutional affiliations.

\section{Submit your manuscript to a SpringerOpen ${ }^{\circ}$ journal and benefit from:}

- Convenient online submission

- Rigorous peer review

- Open access: articles freely available online

- High visibility within the field

- Retaining the copyright to your article

Submit your next manuscript at $\boldsymbol{\nabla}$ springeropen.com 